\title{
Yesterday, today and tomorrow - constant change
}

\author{
Peter Reader
}

[bionote]

Peter Reader has been Director of Marketing and Communications at the University of Portsmouth since March 2008. A graduate of the University of Leeds, he has held posts in six UK universities, including Director's posts in Southampton and Bath. Previously a member of AUA's Executive Committee, Peter was the founding chair of the ACU's PR, Marketing and Communications Network, a position he held until November 2010. Address for correspondence: University of Portsmouth, 28 Guildhall Walk, Portsmouth PO1 2DD Tel: +44 (0)23 9284 5654; Email: peter.reader@port.ac.uk

\section{This paper originated from the closing keynote presentation at the Association of Commonwealth Universities PR, Marketing and Communication Network conference in Melbourne, 24 to 26 November 2010}

It is not so long ago that universities shunned words such as 'public relations' and 'marketing', preferring to describe staff working in these areas as information officers and even assistant registrars and with such staff drawn from a cadre of generalist administrators. If they really had to be specific, then an acceptable word was 'publicity'.

But changing times bring changing needs. And whilst, for example, PR professionals have long talked about the fundamental of public relations being to build mutual understanding between an organisation and its publics, today this readily translates into the essential need for universities to engage with their stakeholders.

\section{Yesterday}

Traditionally, PR in universities was a mix of media relations and events, with the precise mix for the institution tailored to its particular mission and location. Media relations were largely reactive, dealing often only with the media based locally, with events built around the academic community rather than the public. In essence, the role was passive with the focus of media relations being, for example, to deal as necessary with the upsets sometimes caused by students and balancing this with some 'good news' stories, to reassure the local public that their university was doing good work. Event programmes celebrated the work of the academic community, irrespective of the relevance to the wider community.

And as for marketing and brands, they were words never to be uttered despite, ironically, the former word appearing in the course listing in the prospectus. Yet, in their early life, the polytechnics were much more of a market than universities are even today. All applications were made direct, there were no restrictions on competition and other than a gentleman's agreement on advertising, which in any case a number chose to ignore, institutions competed hard for students.

The tasks though were very similar. We placed the advertising, wrote and published the course prospectus and the annual report - the latter going unread, even back then - sent out the press releases, organised events of all sorts, including schools visits, and produced the internal newsletter.

But it was a much simpler world too with telephones into which people used to speak, memos as the normal means of office communication, and, yes, people used to talk to each other. There were no personal computers let alone www or social media, and just a handful of terrestrial TV channels, with cable and satellite television still many years away. Commercial radio was still local, with only the BBC broadcasting nationally.

As for universities, collegiality was still a watchword. Students were still students, universities delivered an education, rather than teaching and learning, and academic democracy, rather than 'management', was still the prime driver of governance. They had registrars not chief operating officers, staffing not human resources, and halls of residence rather than business services. 


\section{Today}

Today so much has changed, starting with students. Who are they, what are they and what is their relationship with the institution? The 1994 Group's work on student experience has considered students as learners, citizens, colleagues, consumers, scholars, ambassadors and partners. But in today's fees-driven universities, are they now investors, investors in their own futures?

Communications, PR and marketing are essential in a modern university, but not only does today's role extend well beyond these core activities but also a modern university needs to engage pro-actively with, for example, specialist staff dedicated to the work, often on targeted activity and campaigns. Reputation management remains at the core of activities, ever more so as most commentators agree in the fees debate, but there are huge changes in the planning of activity, aligning this ever more closely to institutional mission, working alongside both marketers and academic staff and supporting them in meeting their objectives, and engaging both with an ever-wider media landscape and a wider set of stakeholders.

Ironically, though, whilst many communications and marketing professionals come now into universities from the commercial world, some struggle in the rather different academic environment. Take public relations. For these staff, it is a skill to bring to the public the range and diversity of views, including the controversial, in a way that demonstrates the value of universities to wider society. Careful management is now required to achieve a balance of coverage that reflects the academic mission of the university; simply following the external news agenda can result in an institution gaining a public profile which is not aligned with the work of the university.

And pro-activity means a PR team should not only advise on communication strategies but also lead on the training of staff. Expecting the PR team to provide media training for academics and scientists, as well as for institutional leaders, is now the norm. Detractors may claim this can result in 'spin', but engaging with the wider public through the media is an extension of the fundamental work of any university, in order to extend access to knowledge.

But not only is the role different, so is the make-up of the media. Audiences have splintered into a multitude of digital channels and platforms, and social media and web developments are an essential part of key tactical priorities for all education marketers and communicators. In simple terms, the media has proliferated, not only with 24/7 news but also with the explosion in available channels. The traditional channels of print, radio and TV have been joined by social media, web 2.0, making it impractical for any university to 'control' its profile; the best that can be achieved is to 'influence'.

And the speed of change is immense. In five years, Facebook has gained over 400 million regular users, Twitter has 75 million users and has already passed 20 billion Tweets. Six billion people now have mobile phones; 234 million of them own a Smartphone. And in some groups of users, using social media has overtaken the use of Google search as the preferred method of getting new information. What next? And how quickly will it hit us?

This has changed the role of the communications and marketing professional in the modern university, who now has to be a key adviser to institutional leadership, requiring open and sometimes immediate access to the head of the institution, assessing opportunities and providing professional judgement, and advising on everything from the tone of messages to course portfolio management.

Inevitably, there will be a convergence with (corporate) planning function as the need to research and understand markets grows and data become ever more analysed. Universities have a fundamental belief in the value of research yet, ironically, this belief does not always extend outside the academic part of the institution. How many universities have launched new courses not because a market was identified but because the staff wanted to teach their specialist subject - vanity courses? Portfolio management becomes ever more vital.

Maybe in time, with greater emphasis on market research and market intelligence, marketing and planning will simply merge.

But other changes are occurring too. New media channels, blogs, wikis and lifestreaming (individuals streaming video content straight to the web live) bring new demands. Blogs provide both information and misinformation; Facebook and other social media groups can be problematic, attracting hundreds, 
sometimes thousands, of members, but with no 'control' of content, let alone certainty that any information is even accurate.

It's not though all about technology: even more mundane elements of marketing and communications are changing too. Take events management. A direct consequence of more stakeholder engagement is the need for a greater diversity of events, targeted at addressing differing stakeholder needs rather than just those of the institution. Events have to be managed as a planned activity to professional standards, with specific events created to provide the opportunity for engagement with target groups. If universities are to be compared with the best, then events must stress quality at every opportunity.

And love them or loathe them, league tables are a fact of life in higher education. Of course, some still hope they will go away. But, as some years ago John O'Leary, then editor of The Higher and currently editor of the Times Good University Guide, wrote 'British tables, started in The Times, are now published in a half a dozen newspapers, proof there is a public appetite for information and the public see them in a different way to universities.'

So they are here to stay; it's as simple as that. Of course, some argue they are irrelevant. At an OECD conference in Paris in September 2010 the Vice-Chancellor of California State University described global rankings as 'a disease'. Intriguingly he also disagreed that top-ranked universities like Oxford and Cambridge were better than others. 'They are different, they are no better', he said. 'All universities are good because they add value to what we do.'

I'd argue we all need to understand better both how the various league tables work and the impact of each one, and how we can present our own university in the best possible way. Some areas can be influenced fairly directly, such as by the tariff scores of students admitted and the award of good degrees.

All I have written points to greater professionalism, and this is reflected in the way professional groups have emerged. Whilst many of the early higher education communicators and marketers were drawn from the ranks of general administrators, pre-1992 there were two well-established professional groups, the Standing Conference of University Information Officers (SCUIO) and the Polytechnic Public Relations and Information Services Conference (PPRISC). The growth of these groups reflected the increasing specialisation and a drift towards recruiting those with specialist skills from outside higher education rather than those with knowledge of higher education, but limited specialist skills.

SCUIO and PPRISC were the first professional groups to merge in response to the transmogrification of polytechnics into universities, actually a year in advance of the change, becoming in 1991 the Higher Education External Relations Association (HEERA).

And the increasing importance of international work was reflected in the creation, in 1986, of the European Universities Public Relations and Information Officers Association (EUPRIO), in 1994, of CASE Europe and, in 2003, of the Association of Commonwealth Universities PR, Marketing and Communications Network.

But increasingly, and as regrettable as it may be to some, the needed professional skills can only be found by hiring staff from outside the university. Professional training for these staff has to be portable, from professional bodies such as the Chartered Institute of Marketing (CIM) and the Chartered Institute of Public Relations (CIPR). Of course, there is still a place for academic qualifications, particularly master's courses, but non-accredited courses which do not lead to credit accumulation are less likely to be popular with staff.

\section{Tomorrow}

But what of the future? A November 2010 French government survey which ranked public institutions by graduate students' employment rates after graduation drew both praise and criticism. Thoughts must turn surely to some measure of a university's financial position - and how might fee levels be included and, possibly, be combined to show, well, purport to show, value for money?

So where will we be in five, ten, twenty years' time? Of course, we will still have endless meetings no matter how much managers think they manage, our academic communities are still based on collegiality - and the paperless office will still be a wild dream, but the pace of change will be ever faster. Consider the 
pace at which Facebook, Twitter and LinkedIn have become part of our lives, and then consider their age. The simple fact is the technologies of ten years' time have not been developed yet.

At institutional level, markets will be more internationalised, but will institutions? Alliances and conglomerates may emerge, and not-for-profits can operate transnationally, but the notion of a university from one country taking over a university in another flies in the face of nationalism. With the high value placed on higher education, and its vital economic importance, it is inconceivable to think that any government will relinquish its stake in its own country's future.

Putting aside the merger of many smaller institutions into larger neighbours, and the death of the monotechnics, to date in-country mergers of institutions have been relatively rare. But an ever-increasing number of countries, from Wales to Sweden, are encouraging the merger of universities into larger institutions. This is logical, in part to retain international competitiveness and, in part, in the face of the current economic climate. In my view, this will continue, perhaps accelerate.

Some suggest full-time students will become a rare breed. But this ignores the fact that higher education is a sociological as well as educational experience. The social side of higher education cannot be ignored, just as marketers know place and location are as important selection criteria as the course and the institution.

PR, communications and marketing in universities will be still more professionalised. The days when a generalist administrator spent a few years in PR, marketing and communication before going back into the registry or the secretariat will be long forgotten. 